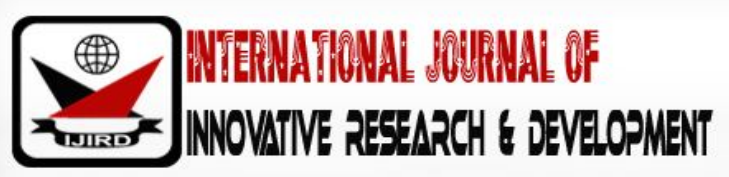

ISSN 2278 - 0211 (Online)

\section{Exploration of Local Materials as Make-Up Kits for Stage and Film Productions in Ghana}

\author{
Johnson Edu \\ Lecturer, Department of Theatre Arts, University of Education, Ghana
}

\begin{abstract}
:
Makeup is a key element in the transformation of the actor to enhance the illusion that the actor has become the character. However, owing to the unavailability of standard makeup kits on the market, both stage and screen makeup artist in Ghana are often handicapped in their attempts to create the desired illusion. This paper seeks to explore the possibility of identifying local materials that could be convenient substitutes for some traditional western makeup kits, in an attempt to establish a stock of makeup materials for a sustained artistic industry. Ultimately, this exploratory research aims to primarily make available alternative makeup kits for teaching and learning purposes as well as for professional usage for stage and screen. It is hoped that the results of this study would not only provide more cost-effective alternatives, but also circumvent the practice whereby many artists utilize inappropriate materials with sometimes, ridiculous effect both on stage and screen. Through explorative research design tinged with experimentation, the author investigates innovative alternative by identifying and developing local food stuff like cassava, plantain and kneaded bread flour among others as makeup inputs.
\end{abstract}

Keywords: Illusion, transformation, makeup, traditional, local, materials

\section{Introduction}

Theatre and film in Ghana of late has taken centre stage in the creative arts industry as far as education, information and entertainment are concerned. This indicates that Ghanaians have developed great interest and appreciation in the arts in Ghana. These artistic forms largely employ visual elements like make-up, set design, props and costume to enhance and give better understanding to the theme of the production. Every theatrical work begins primarily with an idea or a script which is artistically interpreted by the design team members under the supervision of the director who then becomes the inspirational leader of the production team. Among the personnel who contribute to the visual statement of the production are the set, lighting, costume designers and make-up artist. As a matter of fact, these personnel collaborate to produce a unified artistic concept that translates the director's intent and purpose with the view to interpreting the play text into visual statements in order to ensure clarity and meaning for the audience. However, the designers in some instances go through disagreement and conflicting views whiles contributing to the success of the project in the bid to settle on the most appropriate interpretation and spectacle that would appeal to the senses of the audience in moment time and space. In the end, they finally compromise, resolve and settle on an appropriate visual image for a coherent visual impact. (Gillette, 2000).

Undoubtedly, the direction, vision and the success of the production process lies in the hands of the director who dreams the big picture and has oversight responsibility over the production team members. Adjei (2014) reiterates the fact, that playwright's performance text promotes ideas that are carefully interpreted artistically by the design team under the supervision of the director who happens to be the visionary.

Gillette (2000) supports the idea of Adjei regarding the directors' responsibility by clearly indicating that, "one of the primary jobs of the director is to mold these individual artistic ideas and expressions into a unified vision of purpose and intent. Adolphe Appia (1862-1928) and Edward Gordon Craig (1872-1966) built the theoretical foundations of modern expressionistic theatrical practice which focus the efforts of the production team under the supervision of the director. Unquestionably, the production process brings the production design team together to collaborate their efforts in creating the desired illusion based on the production approach with regards the total visual statement.

Costume and make-up, set, light and props design create a dynamic synergy to promote dramatic unity and spectacle. As a matter of fact, these elements tell the story, reinforce the team, define the locale and provide the dominant emotional quality that sets the tone of the play to express the setting. Apparently, the design ideas are controlled by the style, referred to as the spirit of the play. 
When auditions are done and the director blocks the show, the actors rehearse and memorize their lines and deliver them on stage with the assistance of the stage manager under the leadership of the director. At the end, costume and make-up help to identify their role and the personality. This is because what a person wears, that is costume and make-up to a large degree communicate non-verbally to the audience sensibilities about his personality: emotions and idiosyncrasies, because costume and makeup should "reflect the mood and style of the production" (Tanner, 2002:294).For every theatrical production, while the rehearsals are ongoing, makeup and costume needs are being identified by the costume designer and addressed, based on the various roles and demands of the script. Basically, they enhance the role and define appropriately the socio-economic status of the character, religion, culture and gender among others. These elements ultimately define the role played by the actors.

According to Adjei (2014, p.134) costume may hide deformities in the body but cannot be used to cover the blemishes and deformities in the face." The need for make-up is imperative as it boost confidence and transforms the actor into the character. In fact, it is an easy way to manipulate what we look like and the message we send about ourselves. Certainly, it is true for the impression of personality which is conveyed to other people; a person is rated significantly more favorably with cosmetics (standard facial make-up and hair treatment) than without cosmetics as stressed by (Buchman, 1990:269):

"Of all the scenographic elements, costume and make-up are physical and symbolically closet to the actor and his character. Both depend on the actor's physical form for the foundation on which they are built, and both often serve significantly to alter that form in developing the character...Basically, the costume and make-up should visually fuse into the character so thoroughly that only the sophisticated theatrical expert can separate the parts. The close interdependence among elements relate to character is one of the most telling examples of the organic nature of the theatrical art."

The role of costume and make-up cannot be overemphasized as discussed by Buchman due to its peculiar nature in altering the form and features of an actor in developing the character to suit a particular role. For instance, "the character's role itself provides clue to make-up. A character's age, health, occupation personality and attitude must be reflected in makeup. For example, a young character who plays tennis everyday should have a ruddy or tanned face to look like an athlete" (Tanner, 1992:270).

Currently, in this $21^{\text {st }}$ century, most men all over the world have sort to shave off their hair for several reasons. Some stress the fact that, they are growing bald, others say they are growing grey. For such and more reasons they decide to trim every bit of hair grown on the head. Graham (1983) states the implication of such psychological effects arising from the use of cosmetic are particularly important when one considers their role not only in influencing everyday encounters and interview situations among others, but also in promoting psychological wellbeing as aging occurs and in the onset of, and recovery from, mental and physical health. Adjei (as cited by Asiedu, Collins, Gbormittah and Nii-Yartey, 2014:132) is of the view that:

"In our daily life there cannot be make-up without an individual, likewise in the theatre circles there cannot be make-up without an actor, thus the actor is the main recipient of the art. In order for the make-up artist to transform the actor into a stage character, it is expected that the make-up artist studies the play, to get acquainted with the total number of actors and also settle on the kind of make-up needed for each of them."

Playwrights have a way of describing their characters; animals, witches and spirits among others, and designers also see these ideas as technical challenges to solve. Besides, some characters may have certain deformities or peculiar transformations which have to be achieved by the make-up artist through special effects. These physical manifestations become tasks that has to be achieved and solved by the designer. The make-up artist through research translates these ideas into visual artistic language through series of conceptual drawing approaches to be approved by the director for implementation. During this process, what follows next is the selection of the specific make-up effect from the numerous suggested thumb nail sketches as per approval by the director to be applied or constructed on the actor to assume the character to play the role.

The implementation process of the make-up at this stage is critical, since most standardized makeup kits needed for the task are not readily found on the market. Even those material available are very expensive to purchase on the Ghanaian market and in some cases not even available to buy, very demoralizing and frustrating. Unfortunately, the unavailability of make-up materials on the market, to some extent, compel a number of artists to compromise on standards to settle on mediocracy, thereby producing substandard quality work to the audience.

Ironically, Ghana like most African countries are endowed with rich natural resources which hitherto have remained untapped in several cases. Make-up presents such scenarios to be explored. It is on the basis of this, the focus of the paper sought to promote the idea of the exploration of traditional food and local materials as close substitutes to conventional makeup materials.

\section{Theatrical Make-up and transformation}

Basically, make-up is a theatrical element that creates an illusion or make-believe. It transforms an actor into a character to play a designated role which should be convincing and meaningful.

On the other hand, the definition of make-up is always interwoven with costume, because costume and make-up are inseparable elements. Anderson and Anderson (1999, p.18) affirm that "anything worn on stage is a costume, whether it is layers of clothing or nothing at all. A costume is technically defined as dress in general, including underpinnings, accessories, 
hairstyle and make-up." From my point of view, which I think is the opinion of most technical theatre scholars, costume without make-up is not complete. These elements are fashioned on the same ground and their relatedness is unique in design concept and application. You cannot wear costume without make-up, or make-up without costume. Both visual elements blend to promote and protect the character or personality. Barranger (1976) argues that, make-up enhances and completes the costume. He further indicates that it is essential to the actor's visibility. Because in a large theatre, distance and light make an actor's features without make-up colourless and indistinct.

Indeed, Adjei's (2005) position here admits that "costume develops and enriches a performance and it includes all the body garments worn by the actor including make-up and ornaments" (p.34). In another breath, Wilson (1988, p.370) defines costume as "the application of cosmetics; paint powder and rouges to the face and body." Both scholars in their assertion indicate the fact that costume and make-up are either worn on the body or applied to the body.

Bellman (1983) expounds that, "costume and make-up are close to the actor both physically and aesthetically."

Wilson $(1988,370)$ is of the view that makeup is the "application of cosmetics (paint, powders and rouges) to the face and body. From Wilson's exposition it is clear that the human body serves as canvas for the application of the cosmetics. Harrison (1998) bridges the gap between Bellman and Wilson's definition with regards to the materials employed in makeup. He declares that "makeup is the application of grease paints, water-based paints and latex among others to alter the appearance of an actor's face." Carson (1990) in his search confirms that there is a relationship that exists between make-up and art in that, "make-up is a form of art" and it is about technique and art (p. 69). However, if the artist masters the technique without the art he will compromise on the artistic impression, because this art form develops the mood of the actor's characterization and greatly affects the audience's perception of the role played by the actor in projecting a make-believe scenario. Even though in life there is a clear separation between life and the virtual, some audience confuse the real life of the actor and the illusionary life as far as the transformation made by the actor from one world to the other, believing that the actor somehow has "become" the character he is playing. In some instances, makeup could be referred to as costume in the case where the body of the actor is painted to reflect a symbolic apparel or adornment. Notably, the costume designer is responsible for the make-up artistry for any performance since there is the need for both elements to create a synergy to enhance understanding.

\section{Types and Functions of Theatrical Makeup}

There are three basic types of makeup used in stage and screen productions. The first is straight makeup which could be referred to as (everyday wear makeup) it is simply applied to make an actor look better on stage or screen. It employs materials that can be found at any cosmetic shop. These include, powders, lipsticks, blush and lotions to provide pigmentation. The second type of makeup, is referred to as character makeup. This is designed to change the appearance of an actor so that he or she can play a completely different character. The third type is also called special effect makeup. This may employ a combination of makeup and mechanical devices to create an inhuman appearance such as animals, monsters, fractures and cuts. In order to pursue make-up artistry as a student or professional, it is very necessary to distinguish the different forms of makeup.

\subsection{Straight Makeup}

Straight makeup highlights the actors features to reveal facial contours, form and attitude. It also pronounces distinctiveness and visibility as far as the search for uniqueness is concerned as depicted by certain ladies. Delamar refers to straight makeup as:

The basic technique in make-up artistry which may incorporate corrective make-up and camouflage make-up. It can overlap into beauty and fashion but its real function is to enhance, to correct and to define the person's face, rather than to change it. Straight make-up is applied to news announcers and other people being interviewed, modern day drama and soaps among others (2003).

In the provision of straight makeup, beauty therapists also provide services in dyeing eyelashes and removing unwanted hair on the face or body by plucking, waxing, sugaring, bleaching or by electrolysis. They are trained in giving aromatherapy and other massage treatments plus tread vein treatment to enhance an individual's personality (Delamar, 2003). Straight makeup is designed to alleviate discernable visual changes in appearance that can occur as a result of film, television, or theatre process.

Palma (1985) states that, the word makeup in Italian, is trucco, and it is probably derived from an ancient provincial word that means to cheat or trick. Most ladies normally make-up for work to look good and admired by people who will come into contact with them. Makeup is very important to all and is often the key to most people's credibility and success. And, of course, the makeup job depends largely on the ability and skill of the make-up artist to trick, mystify and to create. Seemingly, it appears that, men think straight makeup is the reserve of ladies, no! This medium was created for all genders, the young and the old. It appears that, most elderly women keenly use the kits to their advantage to stay young, sweet sixteen or better still, refusing to grow as some may term it. Why not men? Unconsciously, some men makeup unknowingly when going outing or for work. They look in the mirror to either brush their hair, comb their hair or fix their beard and moustache to feel great. Obviously, some men do apply some foundations and power on their face as well as pomade to look fresh. Yes, that is a form of 
makeup. It is an element we cannot do away with as a person. For example, if one does not comb his hair or freshens up before he goes to work, on arrival he/ she might be labelled for an awkward personality. Make-up not only modifies your features and change your appearance, but it also enhances one's face and makes him/her look right. Plate 1 (a) and 1 (b) shows the treatment of straight make-up in a transformation of a young lady with a natural facial appearance with few blemishes juxtaposing a well made-up face of the same lady, revealing a much more brighter and smoother facial appearance. Materials applied for the transformation were brown and gold foundations, eye lid extensions, black liner, mascara, a lip gloss and a setting powder to complete the process. The aim of this type of make-up is to cover blemish spots, enhance beauty and to ensure a smooth tender skin. Hence, straight makeup does not distort physical body parts nor recreates a body extension. This is why most professionals refer to it as an everyday make-up. It can be used anytime, anywhere and by anybody.

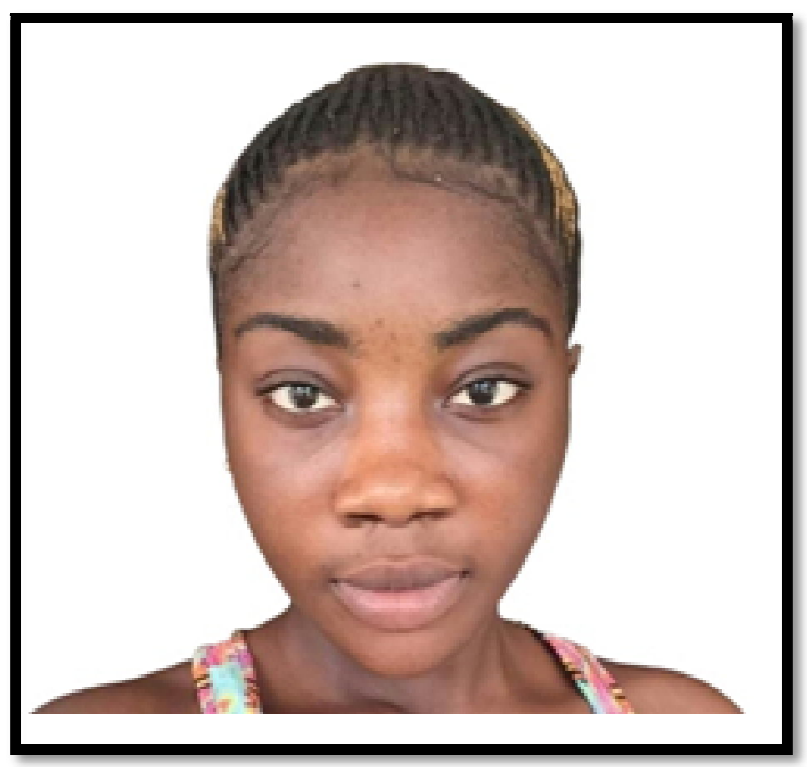

Figure 1: Before Transformation

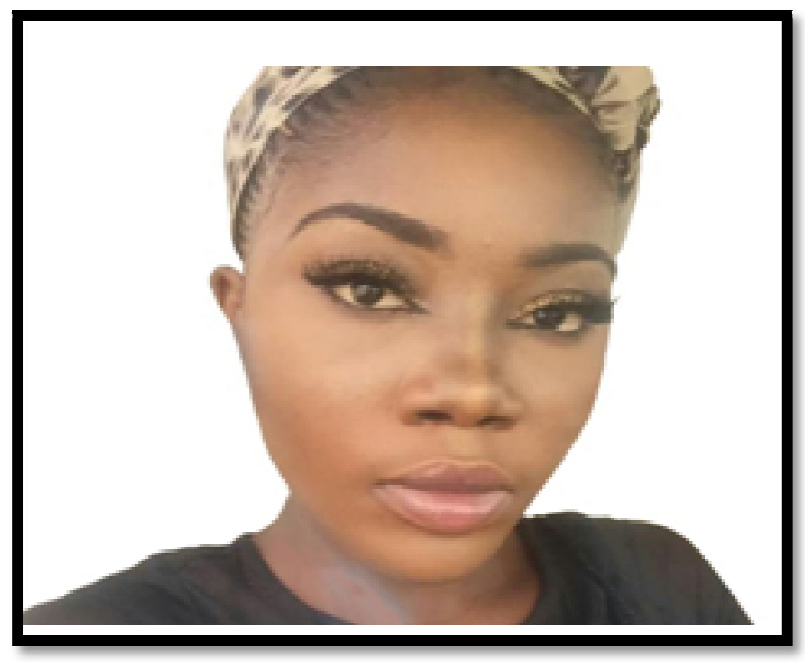

Figure 2: After Transformation

\subsection{Character Make-up}

On the other hand, character makeup transforms the actor's features to reveal age, attitude, wrinkles, nose distortions, eyelashes, jawlines, eyebrows and hair among others which can be used to transform the actor's personality or appearance drastically. It can also be used for fantasy make-up as well as science fictions and monster make-up, Character, as posits by Moodie (1992) is sometimes called illustrative which can make a young actor turn into an older actor. See plate 2(a) and 2 (b) for transformation process by the author during one of his lecture session with students from the University of Education, Winneba, Ghana. The pictures show a young lady of age twenty in her natural look, yet to be transformed into an old lady. Plate 2 (b)also shows visual details of the same lady transformed into a seventy-year-old woman. The transformation was achieved with the use of make-up kits such as, tones of brown foundations, black and grey eye liners and white clay. 


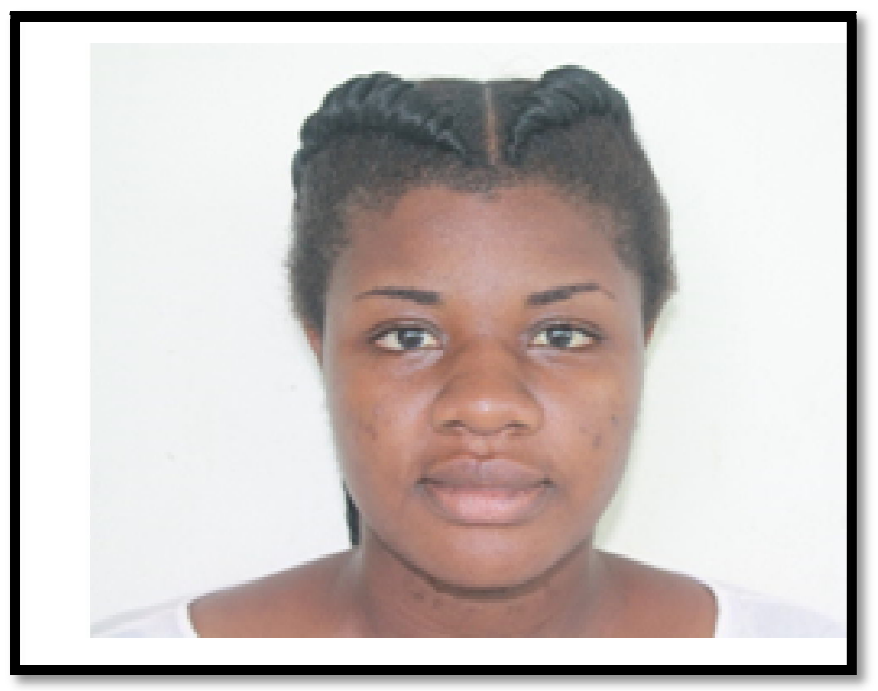

Figure 3: Before Transformation, Natural Face

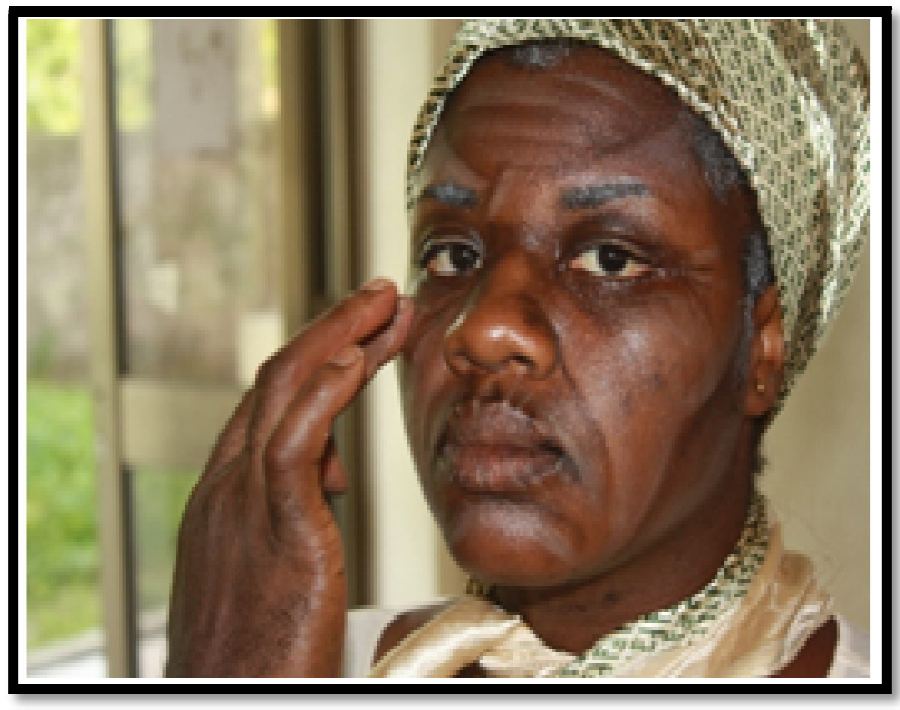

Figure 4: Final Aged Transformation

Certainly, it isn't possible to list and explain all the techniques that make-up artists use for every possible effect. However, the development of make-up largely depends on a process, imagination and resourcefulness. Palma (1985) clearly puts, "many of the procedures that make-up artist use today was invented to fill a need with no previous techniques on which to build" (p.109).

To achieve a close reality of character transformation, it is always imperative to work from a reference visual point, because the technique applied relies on details and precision for execution. Interpretation from the audience point of view must be convincing to tell the story or establish the correct character to play the role effectively.

\subsection{Special Effect Make-Up}

Special effect make-up is an element that creates cinematic magic. It is a process that is used to totally transform the actor drastically to assume a different personality or trait (Duncan, 2006). The medium of special effect is used to create wounds, boils, increase human body size and accident scenes to mention a few. It undoubtedly develops the mood and spirit of the production to the extent that it turns on the emotions of the audience to believe that the act in view is real and natural. In fact, it is one of the powerful mediums used in creating the make believe visual impression. Material such as putty, theatre blood, prosthetics and latex liquid are used for the transformation. However, the use of banku (a local food in Ghana, prepared with corn and cassava dough) has been proven useful as a close substitute for putty. Cooked banku is kneaded with the finger to achieve a smooth texture which is molded to assume the desired shape and then attached to the preferred area. More so, kneaded bread flour is a good material for building up false skin. Plate 3 shows the author demonstrating the use of local material, banku, as a putty to create a severe slash on the left lower arm of one of his students during a makeup lecture session at the University of Education, Winneba, Ghana. 


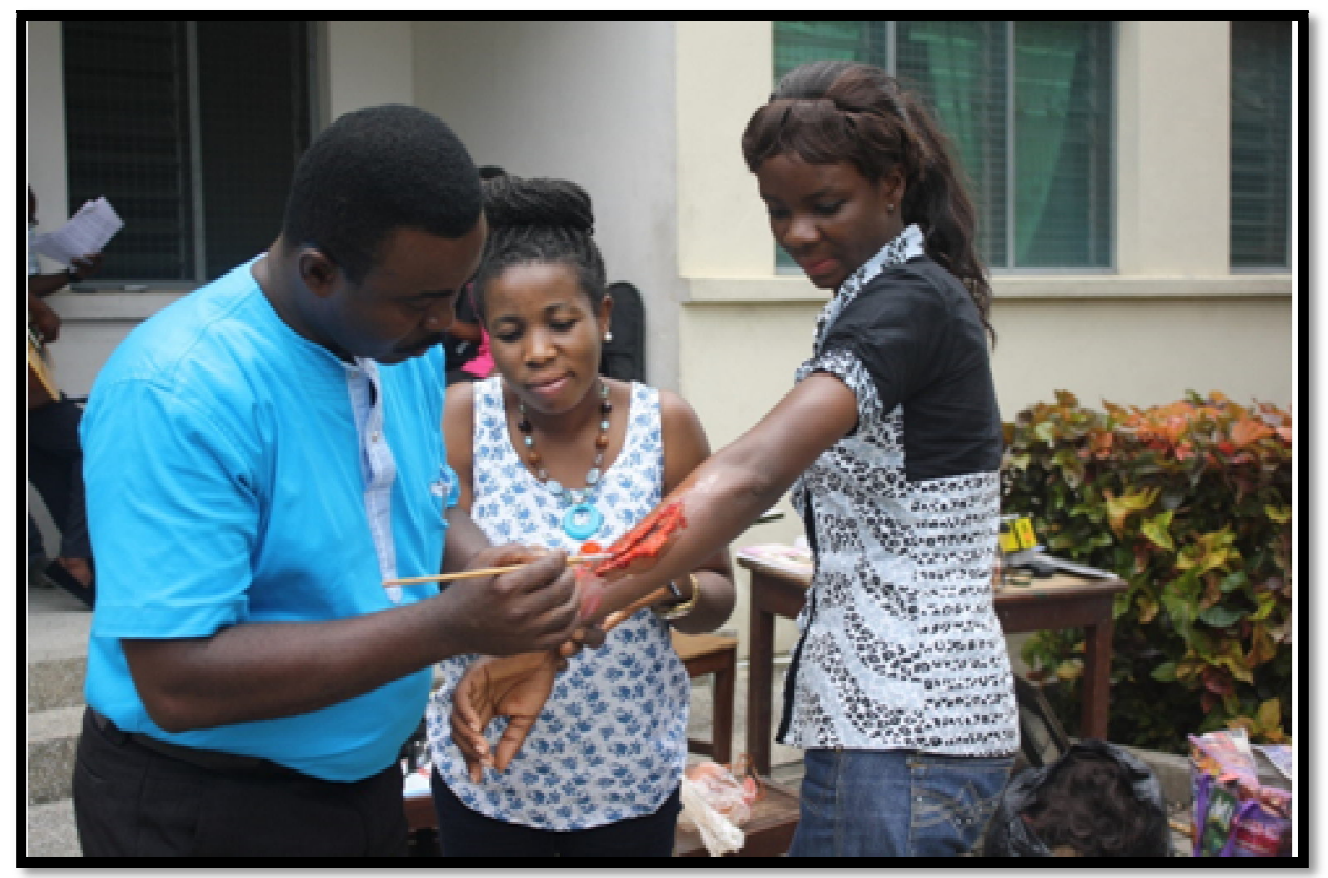

Figure 4: The Author Demonstrating the Craft to Mphil. Students of the Makeup Class of University of Education, Winneba, Ghana, 2016

Materials used for the effect were basically, banku a local food, cotton, theatre blood, different shades of brown foundations that matched the skin tone of the student and red soluble paint to fine tune the texture and quality of blood. Technically, when preparing the set up for special effect, the designer needs to illustrate the concept into visual terms for physical manifestation on object of actor/ actress. This illustration is conceived in a pre-drawn thumb sketch and agreed with the director for implementation or otherwise. All said and done, the actor's body then becomes the canvas on which the makeup mediums are applied for the desired effect. Consequently, there are numerous ways and techniques of makeup design and each artist has his/ her own way of approaching a specific project, even though, there are standard forms of practice.

Ideally, the development of a makeup project largely depends on the process, imagination and resourcefulness of the artist. Palma (1985) clearly puts, "many of the procedures that make-up artist use today was invented to fill a need with no previous techniques on which to build" (p.109). The need for a particular make-up effect causes users of the craft to research and explore ways in identifying materials and applicable techniques for the task.

Special effect makeup is an area that demands passion, dedication, skill and thinking out of the box. In all these, the script becomes the basic reference point for any theatrical production. Additionally, the idea to develop and create special effect can be conceived through the analysis and interpretation of script's text and directorial inclusion. Undoubtedly, itis an element that garnishes the face of a production and often makes the audience sit at the tip of his/ her sit while engaged in viewing a production, be it stage or a film show.

\section{Traditional Local Makeup Materials and their Effects}

In most African countries except South Africa, that boost of film and stage makeup products on their markets, it appears that makeup materials are scarce on most African markets. With particular reference to Ghana, makeup materials and accessories to stock the shelves of shops are hard to come by. Besides, these stage and screen products are generally imported from European countries and very expensive. In the bid to maintain and sustain the theatrical industry in Ghana, some nonconventional makeup materials were identified as close substitutes for make artistry. Putty a building material used in filling cracked wall surfaces of buildings, proves to be a useful material for the design and construction of some rigid body parts like the human nose, jaw and the forehead. It is in this light that Gillette (2000) postulates that "makeup putty can be used to alter the shape of the nose, chin and other nonflexible areas of the skin" (p. 443). Particularly, when creating boils, cut and swells, putty could be used to achieve these effects.

As a result of the unavailability of makeup materials on the Ghanaian market, improvised local inputs are explored for usage to sustain the theatrical and film industry. Among these are fufu a local food in Ghana which can be used to create body parts. Fufu is prepared from the combination of cassava root plant and unripe plantain. Both food stuffs are peeled, boiled and pounded together into semi solid paste form and kneaded with the finger to achieve a smooth texture which is molded into a required shape and attached to desired area. Additionally, garia local cereal is recommended for same purpose asbanku in plate 3. Gariis prepared by pouring boiled water on the grains and then stirred to paste to achieve dough, which could be used for the construction effects like boils, cuts and swells, amazing. Artificial clay dough originally meant for children as a play 
material can equally be used to replace the putty for body construction as well. This can be purchased at the book shops or shopping malls.

To age a character, some visible body features are pronounced for clarity and identification. The grey hair for instance suggests old age. Conventionally, the grey hair spray is professionally used to portray an illusion of an aged character on stage. However, in Ghana, some makeup artist resort to dabbing the hair with loose powder to suggest the grey hair, but that does not last during the course of production. Especially, when the actor changes from one costume to the other, the amount of grey reduces, affecting continuity. Traditionally, the white clay referred to as hyire in the Akan language of the people of Ghana is a better local substitute for the graying makeup product. It has been tested and proven by users as a good product to indicate grey. To use the clay, it has to be soaked and dissolved in a little quantity of water in a bowl to turn to thin textured paste. In applying the solution to the hair, it is advisable to use a bristle hair brush to dab the solution and brush out the hair to achieve the needed effect. It is imperative not to paint the scalp of the actor mistakenly, care must be taken.

Some close substitutes of adhesive materials to secure created features on the body are nail polish, vaseline and hair dressers' bonding glue. These are substitutes for the adhesive spirit gum. Ultimately, when fixing a molded body part constructed out of putty, fufu, banku or gari the recommended adhesive to be applied for stability to secure the mold is the nail polish. After performance, when removing attachment to body part, nail polish remover is used. That is, the remover is gently applied to the area to loosen the nail polish that holds the material to the skin. Similarly, when the hair bonding glue is applied to a unit, its remover is used to detach the unit from the body. In a given circumstance, when a character is to wear a bead or mustache using the hairpiece, the normal practice is to use the spirit gum to secure the hair, alternatively, nail polish or bonding glue could be equally used.

Theatre blood is a product that is not found on the Ghanaian market, this product is always imported from western countries and very scarce to access in Ghana. Hence, there is the urgent need to research and explore ways of producing this but important makeup material. Well, one would say "necessity is the mother of invention." Buchman (1990) a special effect makeup consultant, in his book film and Television makeup explores the process of producing screen blood. In his method;

"to make blood, first pour one karo corn syrup into a clean glass or plastic container and add one-half teaspoon of yellow vegetable colouring and mix the solution. The result has the opacity and consistency of blood. Additionally, one teaspoon of red vegetable colouring is added with a one-half teaspoon of non-toxic watersoluble poster paint is added to complete the process" (p.152).

In fact, this process seems very cumbersome to execute as compared to what the author has developed. As per the authors process, add one-half tea spoon of red food colour into a half plastic cup of glycine and a pinch of blue soluble poster paint and mix, the result is fake blood. Another method is a mixture of one-half portion of water in a clear plastic cup, one-half tea spoon of food colour, a quarter cup of office glue and a pinch of soluble poster colour, the result is theatre blood. One can also blend a quantity of beetroot with a cup of water, a pinch of soluble poster and mixed with a quantity of glycerin in a plastic cup, this also gives a clear result of blood. In furtherance to the process of developing blood, it is realized that when blood stays on the body for a while, it becomes dark in colour and appearance. To achieve this effect, a little quantity of soot or powered charcoal is added to the prepared blood. One important observation is that the improvised blood can be put in the mouth without causing any harm to the health of the actor because food colour and glycerin are consumables. Interestingly, in achieving the effect of burns in a theatrical context, the makeup artist can combine starch and chocolate to produce such an effect.

\section{Conclusion}

When technical preparation such as set, light sound and props are completed and actors ready to mount the stage, makeup and costume as essential elements of illusion are employed to enhance the personality transformed to compliment the total visual impression or setting. Meanwhile, the availability of these materials and facilities are very much essential to the development and production of a stage or film production. As a result of non-availability of standardized makeup kits or materials on the Ghanaian market coupled with the high cost of the few available materials in the shops, it has become necessary to explore local materials for teaching and learning in the Department of Theatre Arts, University of Education, Winneba in Ghana. As a matter of urgency, the Technical unit of the Department of Theatre Art, School of Creative Arts, University of Education, Winneba, embarked on the exploration and experimentation of non-conventional and local food materials as close substitute for stage and film production. This search has conveniently paved the way for performing Art institutions in Ghana to follow suit in this innovative development to make available makeup materials for the teaching and learning process in some Ghanaian Universities in Ghana as well as professional users of the products.

It is envisaged that further research and interest to develop the local material will be given attention. Especially, involving and partnering with scientific institutions to improve and standardize the quality of the product to meet world standards to stock the market both for commercial

\section{References}

i. Anderson, B. and Anderson, C. (1999). Costume Design. New York: Earl McPeek.

ii. Adjei, C. (2005). Developing Costume Design for Theatre and Film Production in Ghana. Theatre Studies in Review. Vol. 5. No.1, p. 24. 
iii. Adjei, C. (2014). Theatrical Make-up in Ghana. In A. M. Asiedu, E. J. Collins, F. Gbormitta \& F. N. Yartey (Eds.), The Performing Arts in Africa-Ghanaian Perspective (p. 132-138). Oxfordshire: Ayebia Clarke Publishing limited.

iv. Barranger, S. B. (1976). Theatre: A Way of Seeing ( $6^{\text {th }}$ ed.). Boston: WADSWORTH CENGAGE Learning.

v. Bellman, W. (1983). Scene Design, Stage Lighting, Sound, Costume and Makeup. New York: Harper \& Row, Publishers. Buchman, H. (1990). Film and Television Makeup. New York: Watson-Guptill Publications.

vi. Carson, R. (1990). Stage Makeup. New Jersey: Prentice Hall.

vii. Delamar, P. (2003). The Complete Make-up Artist: Working in Film, Fashion, Television and Theatre ( $2^{\text {nd }}$ ed.). London: Thomson.

viii. Duncan, J. (2006). The Winston Effect: The Art and History of Winston Studio. New York: Titan Book Limited.

ix. Gillette, M. J. (2000). Theatrical Design and Production: An introduction to Scene Design and Construction, Lighting, Sound Costume and Makeup (4th ed.). New York: Mc Graw-Hills.

x. Harrison, M. (1998). The Language of the Theatre. New York: Routledge.

xi. Moodie, C. (1992). The Five-Minute Eye Make-Over. London: Breslich \& Foss Ltd.

xii. Palma, D. D. (1985). Makeup Artist’s Handbook for Stage, Screen \& Video. New York: Sterling Publishing Co., Inc.

xiii. Wilson, E (1988). The Theatre Experience (6 ${ }^{\text {th }}$ ed.). New York: McGraw-Hill, Inc.

xiv. Internet Assessed

xv. Graham, J. (1983). The Importance of Cosmetic in the Psychology of Appearance. International Journal of Dermatology. Volume 22, issue 3 April. Pp. 153-156. Retrieved from http:/ / onlinelibrary.wiley.com on 26/ 09/ 2017.

xvi. Tanner, A. F. (2002). Basic Drama Project (7th ed.). Logan, Iowa: Clark Publishing.Retrieved from http:/ / www.motcca.gov.gh. On 25/ 09/ 2017 